\title{
BAHAN AJAR FLIPBOOK ONLINE MATA KULIAH PTI MENGGUNAKAN PENDEKATAN AUGMENTED REALITY
}

\section{Online Flipbook Teaching Materials on PTI with Augmented Reality Approach}

\author{
Budi Arifitama \\ Universitas Trilogi \\ Jl. Taman Makam Pahlawan No. 1, Kalibata, Pancoran, \\ Jakarta Selatan 12760, Indonesia \\ budiarifitama@gmail.com
}

\begin{abstract}
ABSTRAK: Pendidikan merupakan salah satu fondasi bagi berdirinya sebuah bangsa. Bangsa yang maju selalu diiringi dengan tingkat pelaksanaan pendidikan yang baik. Di Indonesia, penerapan teknologi dalam pelaksanaan proses belajar mengajar di dalam kelas masih tergolong minim. Proses belajar mengajar masih bersifat konvensional dengan cara tatap muka dan presentasi sehingga siswa sering merasa bosan dan transfer knowledge menjadi tidak baik. Oleh karena itu, perlu adanya inovasi teknologi dalam proses belajar mengajar untuk meningkatkan rasa ingin tahu siswa dan transfer knowledge. Penelitian ini membahas mengenai pengembangan bahan ajar Flipbook dengan pendekatan Augmented Reality. Augmented Reality digunakan sebagai inovasi dalam proses pembelajaran dengan cara menampilkan objek pada materi mata kuliah yang seolah-olah nyata sehingga peserta didik mampu melakukan interaksi dan meningkatkan rasa keingintahuannya.
\end{abstract}

Kata Kunci: Flipbook, Augmented Reality, bahan ajar, teknologi

ABSTRACT: Education is an important foundation for the establishment and development of a nation. Developed nations are always followed with good education services. In Indonesia, technology implementation in learning teaching process is still few. The learning teaching process is still convensional, which is face-to-face and presentation so that the students often get bored and the knowledge transfer is not running well. Therefore, a technological innovation in learning teaching process is required to increase the students' curiousity as well as knowledge transfer process. This research studies the development of Flipbook learning material with Augmented Reality approach. Augmented Reality approach is used as an innovation in learning teaching process by showing certain object which seems to be real so that the students can interact with it and increase their curiousity.

Keywords: Flipbook, Augmented Reality, learning material, technology 


\section{PENDAHULUAN}

Perkembangan dan kemajuan pesat di bidang industri dan teknologi informasi menyebabkan perubahan besar di berbagai aspek dan bidang kehidupan manusia. Kondisi ini mendorong berbagai bidang industri di Indonesia untuk terus melakukan inovasi dalam mengembangkan sumber daya manusia agar lebih memiliki daya saing. Salah satu bidang yang menjadi tonggak bagi tercetaknya generasi penerus yang baik adalah pada bidang pendidikan.

Dunia pendidikan terbagi menjadi tiga jenjang, yaitu jenjang sekolah dasar dengan rentang usia antara 7 hingga 12, jenjang sekolah menengah pertama dengan rentang usia 13 hingga 15 tahun, jenjang sekolah mengah atas dari rentang usia 16 hingga 18 tahun, serta jenjang perguruan tinggi (http:// www.pendidikanekonomi.com/).

Proses belajar mengajar yang baik merupakan salah satu hasil dari persiapan matang dari seorang pengajar yang hendak melaksanakan kegiatan belajar mengajar. Belajar merupakan suatu proses di mana suatu organisme berubah perilakunya akibat suatu pengalaman (Gagne,1985). Segala yang terjadi pada saat dilakukan sesi pengajaran tergantung dari bagaimana seorang pengajar mempersiapkan kelas hingga mampu memberikan arah jalannya perkuliahan dan memberikan pengalaman kepada peserta didik serta memastikan bahwa transfer knowledge dari pengajar dapat diserap oleh siswa sehingga tujuan dari kelas tersebut dapat tercapai.

Pada penelitian ini, yang akan dibahas adalah pendidikan perguruan tinggi di Universitas Trilogi khususnya di program studi teknik informatika. Saat ini, program studi teknik informatika telah menerapkan pembelajaran jarak jauh menggunakan google classroom sebagai penghubung bagi dosen sebagai fasilitator kepada mahasiswa sebagai peserta didik. Fitur pembelajaran jarak jauh yang telah berhasil diterapkan adalah sebatas untuk keperluan penyimpanan materi mingguan, penyimpanan video, pelaksanaan kuis yang terjadwal serta pemberian tugas online. Inovasi dalam pemberian materi menjadi sangat vital, karena penyampaian materi yang baik akan menentukan keberhasilan penyerapan materi oleh peserta didik.

Mata kuliah Pengantar Teknologi Informasi (PTI) merupakan mata kuliah dasar yang membahas perkembangan teknologi dari awal terciptanya komputer hingga generasi mobile gadget yang dipakai saat ini. Peralatan teknologi klasik dari awal 90-an sangat banyak ragamnya. Namun demikian, barangnya sudah langka pada saat ini. Ketika pengajar ingin menjelaskan mengenai peralatan teknologi klasik tersebut, ia hanya menggunakan gambar saja, sehingga siswa kurang mampu melihat dan memahami peralatan teknologi klasik yang dimaksud.

Untuk melakukan inovasi dalam hal pembelajaran jarak jauh, diperlukan beberapa tahapan dalam awal pembangunan. Flipbook digunakan sebagai sarana visual yang interaktif yang dapat digunakan sebagai pembelajaran interaktif untuk meningkatkan kemampuan pemahan siswa (Haryanti, 2016). Beberapa penelitian menunjukkan bahwa pemanfaatan media Flipbook mampu meningkatkan pemahaman siswa seperti misalnya Penerapan Media Pembelajaran Flipbook untuk Pengenalan Kesehatan Gigi (Rikrwarastuti, dkk., 2017), di mana peserta didik mendapatkan pengetahuan mengenai permasalahan yang ada pada mulut dan banagaimana mengolah kesehatan mulut; Implementasi Pembelajaran dengan Menggunakan Media flipbook (Mulyaningsih, 2017); Pengembangan Flipbook sebagai Pembelajaran Elektronika Dasar untuk Anak Sekolah (Hidayatullah, 2016), di mana dilakukan pengembangan Flipbook untuk tema; dan Flipbook sebagai Dasar Pembelajaran Matematika di Sekolah Menengah ke Atas (Rasiman, 2014).

Augmented reality merupakan sebuah teknologi baru di dunia multimedia. Teknoloogi ini hadir sebagai hasil rangkaian pengembangan penelitian yang dilkukan oleh peneliti di awal tahun 1997, di mana teknologi ini merupakan pengembangan dari virtual reality yang menjadikan sebuah benda 3 dimensi hadir dalam dunia nyata (Azuma, 2017). Hingga saat ini, sudah mulai banyak 
penelitian yang membahas mengenai teknologi Augmented Reality seperti pada peneltian Penerapan Teknologi Augmented Reality yang digunaan sebagai Dijitalisasi Kultur Alat Musik di Jawa Barat (Arifitama, 2017). Pada penelitian ini, objek instrumen yang diteliti menggunakan instrumen tradisional wilayah Jawa Barat. Seluruh objek tersebut dibuatkan bentuk 3 dimensinya dan dilakukan penambahan interaksi dengan memanfaatkan Augmented Reality seakan akan objek tersebut hadir di dunia.

Penelitan lain adalah mengenai Pengenalan Bahasa dengan Menggunakan Whiteboard melalui Pendekatan Augmented Reality (Perez, 2017). Pada penelitian ini, Augmented Reality diterapkan pada sebuah whiteboard di mana siswa belajar kata dan kalimat baru dengan mengarahkan alat Augmented Reality hingga mengetahui arti dari kata tersebut. Penelitian selanjutnya adalah Pemanfaatan Augmented Reality pada permainan Othello (Aguston, dkk., 2016). Penelitian ini membahas mengenai bagaimana penerapan Augmented Reality ke dalam sebuah permainan Othello dengan membuat sebuah Marker Board berisikan arena permainan Othello. Permainan akan dimulai ketika kamera mengarahkan pada arena marker yang telah dibuat.

Dasar dari penerapan Augmented Reality adalah pada platform perangkat lunak unity di mana perangkat lunak ini merupakan salah satu platform pengembangan game 2 dimensi maupun 3 dimensi. Selain dalam pengembangan game, unity dapat digunakan untuk mengembangkan teknologi Augmented Reality dengan memanfaatkan SDK tool vuforia sebagai dasar pengembangan teknologi Augmented Reality. SDK ini menggunakan teknologi computer vision untuk mengenali dan melacak gambar target dan obyek 3D yang sederhana secara real time. Jenis marker yang dapat dikembangkan di SDK ini adalah berupa single marker, cubicle marker, cone marker dan environment marker (https://library.vuforia. com/).

Setiap marker yang telah dibuat dapat diunduh dan diekspor ke berbagai aplikasi pengembang aplikasi yang berjalan di desktop maupun di mobile. Dengan menggunakan perangkat lunak ini, pengembang dapat membuat game dengan lebih mudah dan cepat. Plaform yang dapat dijalankan pada unity adalah seperti Windows, Mac, Xbox 360, Playstation 3, Nintendo Wii, iPad, iPhone, dan Android.

Atas dasar pertimbangan tersebut, dibuatlah sebuah inovasi dari bahan ajar online dengan menggabungkan buku ajar berbasis Flipbook dengan teknologi Augmented Reality pada mata kuliah pengantar teknologi informasi sehingga bahan ajar yang dihasilkan akan lebih menarik, informative, dan inovatif. Augmented Reality merupakan sebuah teknologi di bidang multimedia yang memungkinkan penggunanya untuk memvisualisasikan dunia maya sebagai bagian dari dunia nyata yang seakan terhubung dengan dunia nyata serta dapat berinteraksi (Jacobs, 2012).

Dengan dilaksanakannya penelitian ini, diharapkan akan dapat meningkatkan mutu penyampaian materi kepada peserta didik.

\section{METODA}

Penelitian ini menggunakan metode pendekatan kuantitatif, di mana teknik pengambilan sampel menggunakan teknik observasi dan pengambilan kuesioner dengan sampel sebanyak satu kelas dengan jumlah 43 mahasiswa.

Mata kuliah yang dijadikan bahan pada penelitian ini adalah Pengantar Teknologi Informasi (PTI) yang merupakan mata kuliah dasar yang diberikan pada semester satu, di mana mata kuliah ini menjelaskan mengenai perkembangan teknologi secara umum, mulai dari sejarah perkembangan komputer dari generasi awal hingga perkembangan generasi komputer yang paling mutakhir. Bagian dari silabus yang diambil sebagai penelitian adalah perkembangan generasi komputer.

Generasi komputer pertama memiliki komponen-komponen dari tabung hampa, sehingga ukurannya sangat besar. Pada tahun 1946 komputer elektronik pertama di dunia, ENIAC, memiliki bobot 30 ton, panjang $30 \mathrm{~m}$, tinggi $2,4 \mathrm{~m}$, dan bisa membutuhkan daya listrik sampai $174 \mathrm{kw}$.

Generasi komputer kedua menggunakan teknologi transistor sebagai komponen listrik 
dan elektronika, serta mulai memperkenalkan bahasa pemrograman layaknya Cobol, Fortran dan Algo. Generasi komputer ketiga memiliki ciri khas yaitu sudah menerapkan Integrated Circuit (IC), pemrosesan prosesor, dan memori lebih cepat dari pendahulunya, serta memungkinkan untuk melakukan kegiatan secara bersamaan. Komputer generasi keempat dibekali dengan teknologi LSI (Large Scale Integration) yang mampu menyatukan seluruh komponen pada generasi sebelumnya menjadi satu chip. Generasi komputer kelima memiliki ciri khas seperti peralatan komputer yang digunakan sehari-hari seperti desktop komputer, laptop serta kecerdasan buatan.

\section{Siklus Hidup Waterfall}

Metode penelitian dalam pengembangan aplikasi pada penelitian ini menggunakan pendekatan siklus hidup pengembangan sistem Waterfall. Adapun tahapan fase yang akan dilakukan pada pendekatan ini adalah sebagai berikut.

Waterfall terbagi menjadi beberapa fase di mana satu sama lainnya tidak boleh saling mendahului. Menurut Rosa dan Shalahuddin (2013), metode pengembangan sistem merupakan proses mengembangkan atau mengubah suatu sistem perangkat lunak dengan menggunakan metode-metode atau model-model yang digunakan orang untuk mengembangkan sistem perangkat lunak sebelumnya dengan memiliki alur hidup perangkat lunak secara sekuensial secara kebawah dimulai dari tahapan analisis, perancangan, implementasi, pengujian, dan tahap pendukung. Berikut adalah gambaran dari alur Waterfall.

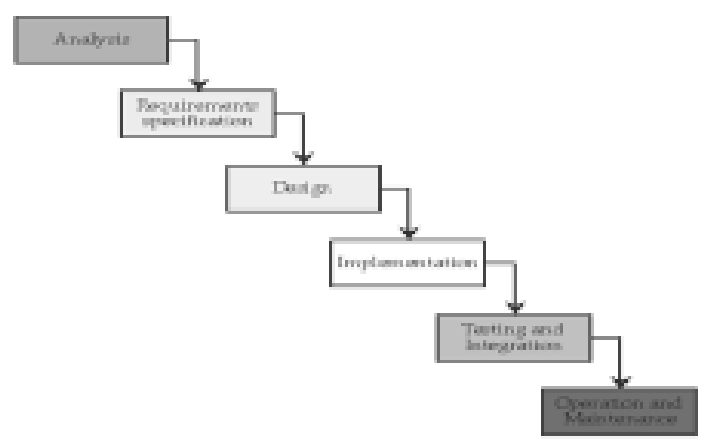

Gambar 1. Gambaran Alur Waterfall
Fase pertama dari siklus Waterfall dimulai dari yang paling atas seperti pada Gambar 1. Fase ini merupakan gerbang mulainya perancangan sebuah perangkat lunak yang baik. Pada fase ini, dilakukan sebuah identifikasi permasalahan apa yang dibutuhkan oleh user sehingga pengembang dapat memperoleh informasi yang disepakati oleh user dan pengembang di mana persetujuan tersebut diikat oleh sebuah perjanjian kontrak di mana user dan peneliti memiliki hak dan tanggung jawab sesuai proporsinya. Peneliti harus mendapatkan segala data dan informasi dari user selengkap-lengkapnya agar dapat diolah dan diberikan kepada fase beriktunya yaitu fase desain untuk perancangan sistem.

Fase yang kedua dari siklus hidup Waterfall adalah analisis desain. Pada tahapan ini, dilakukan perancangan berdasarkan informasi dan data yang didapatkan dari fase identifikasi, dan dilakukan pengolahan untuk membentuk desain model sistem, pengoperasian aplikasi, output aplikasi yang telah disesuaikan dengan analisis kebutuhan pada tahap awal untuk menyelesaikan permasalahan tersebut yang kemudian akan diberikan kepada fase berikutnya yaitu fase implementasi.

Fase ketiga adalah fase implementasi, di mana pada tahapan ini dilakukan proses pengkodean yang dilakukan oleh programmer dari hasil perancangan yang dilakukan pada tahapan sebelumnya. Programmer merancang sebuah script kode pemrograman ke dalam sebuah perangkat lunak dengan bahasa pemrograman yang sesuai dengan tujuan menghasilkan aplikasi.

Fase pengujian merupakan tahapan pengujian akhir dari proses siklus pengembangan sistem. Ini merupakan garis akhir sebelum aplikasi dapat dikatakan layak untuk beredar untuk umum yang digunakan sebagai validasi sistem.

\section{Pendekatan Flipbook}

Flipbook buku adalah sebuah buku dengan serangkaian gambar yang bervariasi secara bertahap dari satu halaman ke halaman berikutnya seperti pada Gambar 2 berikut ini. 


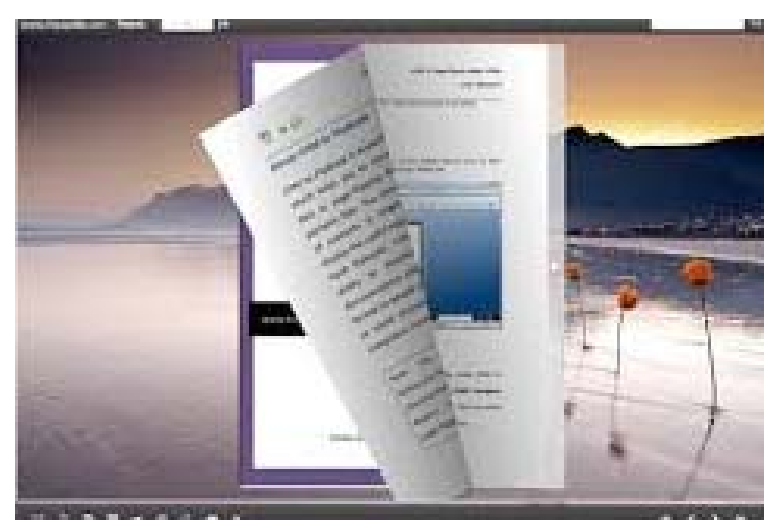

Gambar 2. Ilustrasi Penggunaan Flipbook

Gambar 2 menjelaskan mengenai prosedur Flipbook di mana user seolah olah merasa seperti sedang membaca dan membuka buku elektronik. Flipbook digunakan agar interaksi antara user dan proses transfer knowledge menjadi lebih efektif dan tepat sasaran.

\section{Pendekatan Augmented Reality}

Augmented Reality merupakan salah satu teknologi yang saat ini sedang berkembang, di mana teknologi ini mampu membuat sebuah ilusi optik untuk menggabungkan antara dunia nyata dan dunia virtual dan dapat berinteraksi dengan penggunanya.

Teknologi ini telah lama dikembangkan oleh para peneliti namun baru dalam konsep Virtual Reality (VR), di mana konsep VR mengajak para pengguna untuk masuk ke dalam dunia virtual. Azuma, peneliti dari Jepang, telah berhasil menemukan inovasi yaitu Augmented Reality dengan menghilangkan dinding virtual yang selama ini ada pada teknologi Virtual Reality dan membuat objek 3 dimensi seakan hadir di antara kita.

\section{Prosedur Kinerja Sistem}

Cara kerja dari penerapan Flipbook dan Augmented Reality dapat dilihat pada ilustrasi berikut ini.

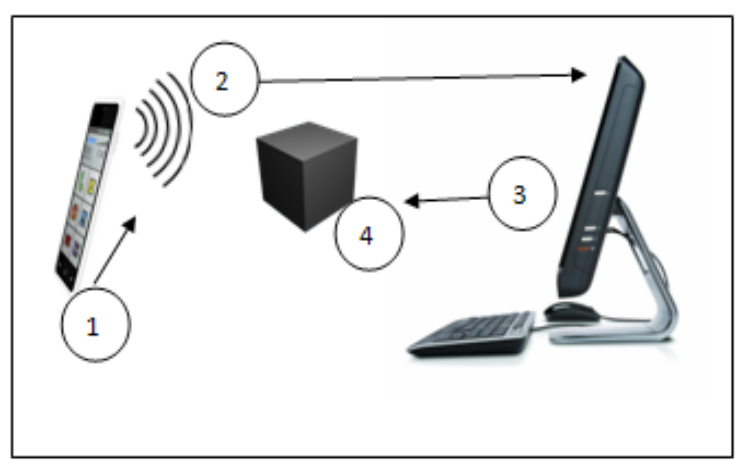

Gambar 3. Ilustrasi Kinerja Sistem

Gambar 3 merupakan ilustrasi penggunaan teknologi Augmented Reality pada penelitian kali ini. Alur sudah tertera pada gambar 3, di mana pertama kali siswa penggunakan perangkat smartphone yang sudah memiliki aplikasi Augmented Reality. Kemudian, siswa melakukan pengindaian pada Flipbook yang sudah ada di media komputer yang tersimpan di Google Classroom. Setelah melakukan pengindaian, objek Augmented Reality akan tampil tepat di atas layar monitor seolah-olah melayang dan peserta didik dapat melakukan interaksi dan mempelajari bentuk dari objek yang dibahas di Flipbook secara lebih interaktif.

\section{HASIL DAN PEMBAHASAN}

Sebelum melakukan pengembangan Augmented Reality, diperlukan pembangunan Flipbook terlebih dahulu sebagai dasar untuk penempatan marker.

\section{Perancangan Desain Flipbook}

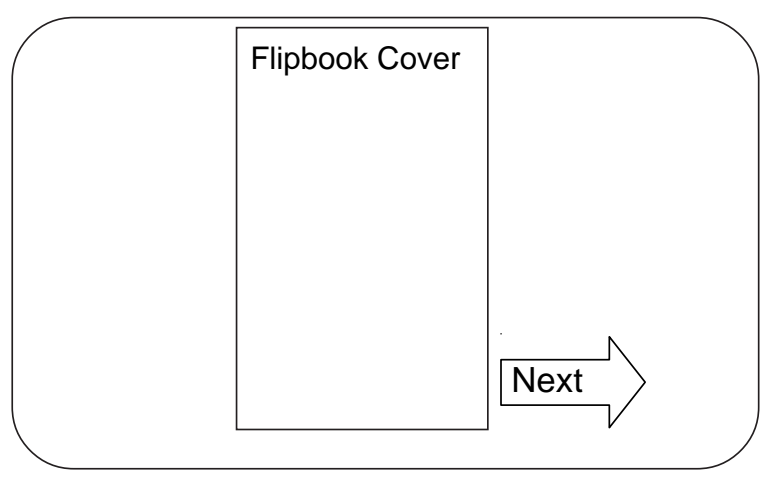

Gambar 4. Ilustrasi Cover Flibook 
Gambar 4 merupakan rancangan Flipbook yang digunakan pada penelitian. Perancangan Flipbook di atas memiliki beberapa komponen sebagai berikut ini.

- Img_Flipbook adalah komponen gambar yang digunakan sebagai cover dari Flibook.

- Button_Next adalah komponen tombol yang digunakan sebagai tombol perpindahan halaman Flipbook dari Cover ke halaman selanjutnya.

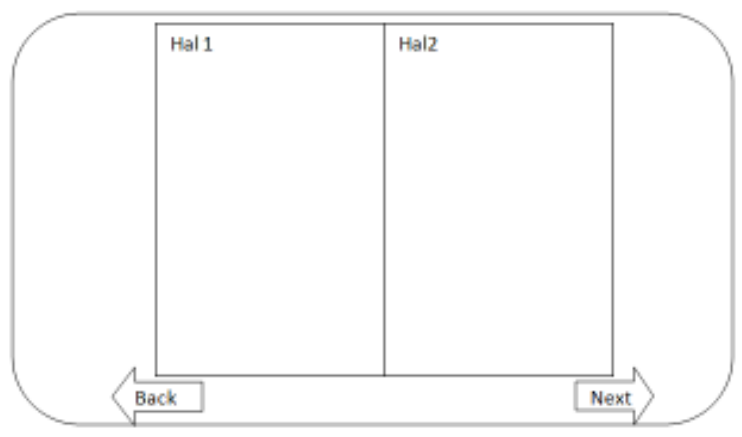

Gambar 5. Ilustrasi Halaman Dalam Flipbook

Gambar 5 merupakan rancangan Flipbook yang digunakan peada penelitian ini. Adapun pada flipbook tersebut merupakan halaman Cover dari Flipbook. Perancangan Flipbook di atas memiliki beberapa komponen sebagai berikut ini.

- Img_Flipbook_hal1 adalah komponen gambar yang digunakan sebagai gambar kedua yaitu generasi komputer ke-1,

- Img_Flipbook_hal2 adalah komponen gambar yang digunakan sebagai gambar ketiga yaitu generasi komputer ke-2,

- Button_Back adalah komponen tombol yang digunakan sebagai tombol perpindahan halaman Flipbook dari halaman saat ini ke halaman sebelumnya,

- Button_Next, adalah komponen tombol yang digunakan sebagai tombol perpindahan halaman Flipbook halaman saat ini ke halaman selanjutnya.

Halaman Flipbook akan berhenti hingga sampai pada generasi komputer keenam.
Hasil Implementasi Perancangan Flipbook

Hasil dari perancangan yang telah dibuat pada tahapan sebelumnya kemudian implementasikan seperti pada gambar di bawah ini.

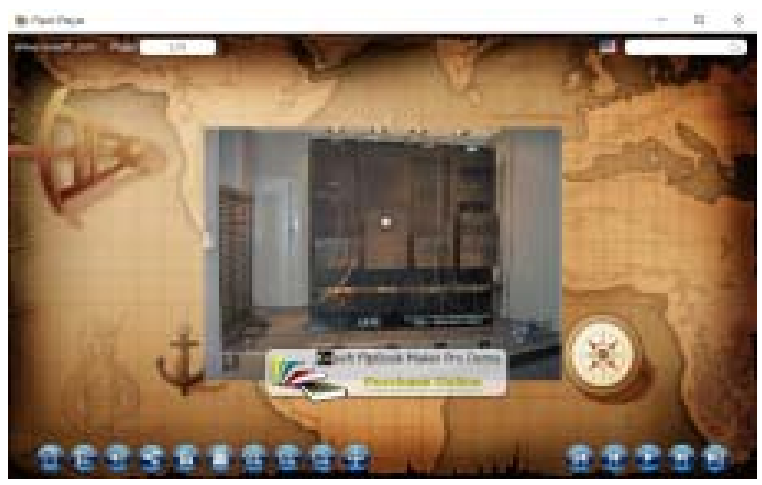

Gambar 6. Implementasi Halaman Cover Flipbook

Gambar 6 merupakan gambar ilustrasi dari generasi komputer pertama yaitu ENIAC. Gambar tersebut nantinya juga akan berfungsi sebagai marker untuk menampilkan objek Augmented Reality.

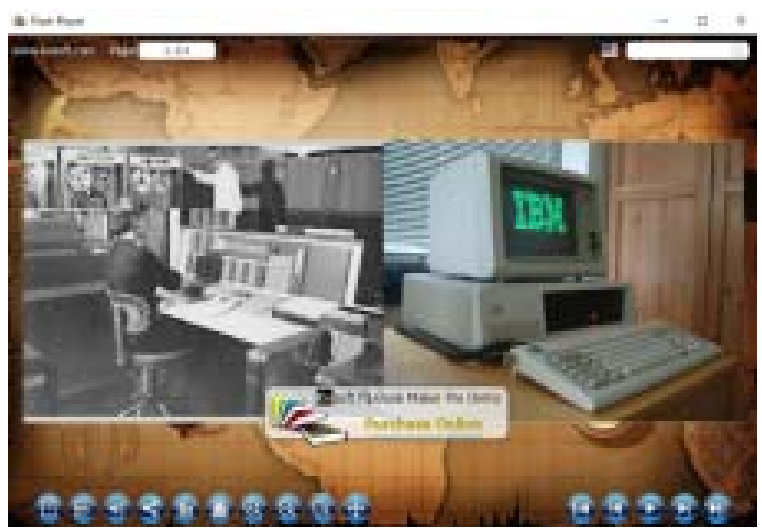

Gambar 7. Implementasi Komputer Generasi Kedua dan Ketiga

Gambar 7 merupakan gambar ilustrasi dari generasi komputer kedua dan ketiga. Gambar tersebut juga akan berfungsi sebagai marker untuk menampilkan objek Augmented Reality. 


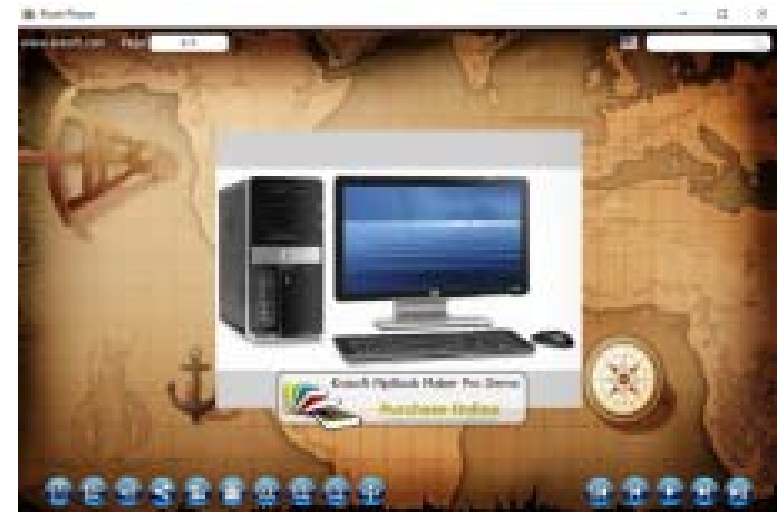

Gambar 8. Implementasi Halaman Generasi Komputer Keempat

Gambar 8 merupakan gambar ilustrasi dari generasi komputer keempat. Gambar tersebut nantinya juga akan berfungsi sebagai marker untuk menampilkan objek Augmented Reality.

\section{Perancangan Desain Augmented Reality}

Perancangan desain objek 3 dimensi untuk tiap generasi komputer menggunakan Google Sketchup, dan menghasilkan beberapa rancangan seperti pada gambar berikut ini.

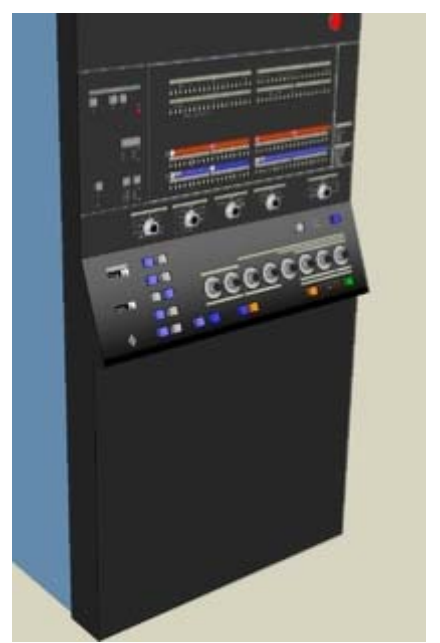

Gambar 9. Perancangan Komputer ENIAC

Gambar 9 merupakan hasil perancangan dari generasi komputer pertama di mana pada perancangan ini diambil berdasarkan model komputer generasi pertama yaitu ENIAC.

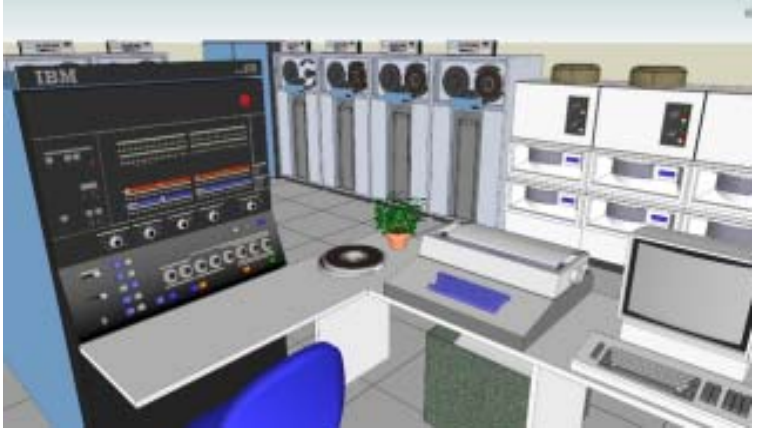

Gambar 10. Perancangan Komputer Generasi Kedua

Gambar 10 merupakan hasil perancangan dari generasi komputer kedua di mana pada perancangan ini diambil berdasarkan model komputer generasi kedua yaitu IBM 370. Pada perancangan ini, tidak hanya satu unit saja yang dirancang, namun satu ruang beserta mainframe juga dibuat.

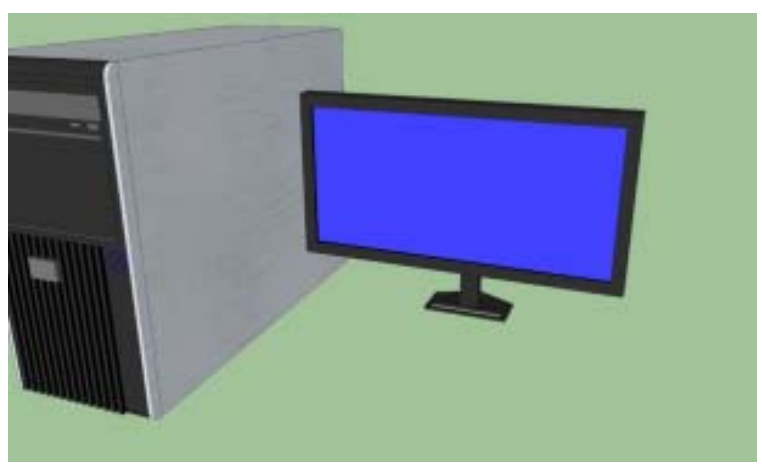

Gambar 11. Perancangan Komputer Generasi Ketiga

Gambar 11 merupakan hasil perancangan dari generasi komputer ketiga di mana pada perancangan ini diambil berdasarkan model komputer generasi ketiga yaitu komputer desktop. Adapun pada perancangan ini dibuat 2 buah objek yaitu CPU dan Monitor.

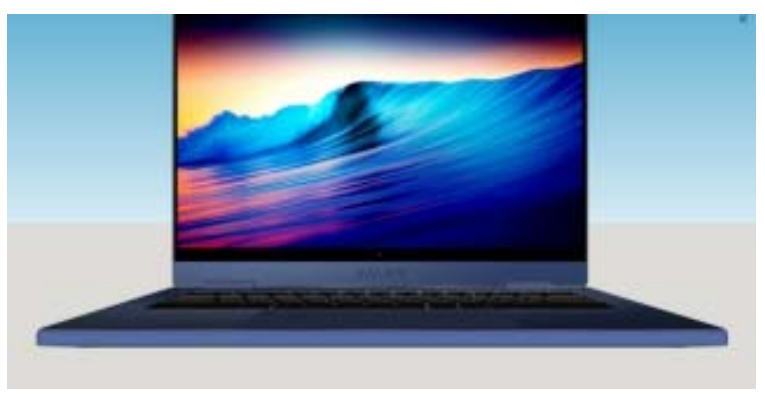

Gambar 12. Perancangan Komputer Generasi Keempat

Budi Arifitama: Bahan Ajar Flipbook Online Mata Kuliah PTI Menggunakan Pendekatan Augmented Reality 
Gambar 12 merupakan hasil perancangan dari generasi komputer keempat di mana pada perancangan ini diambil berdasarkan model komputer generasi keempat yaitu laptop.

\section{Hasil Implementasi Augmented Reality}

Hasil dari Implementasi Augmented Reality dapat dilihat pada gambar berikut ini.

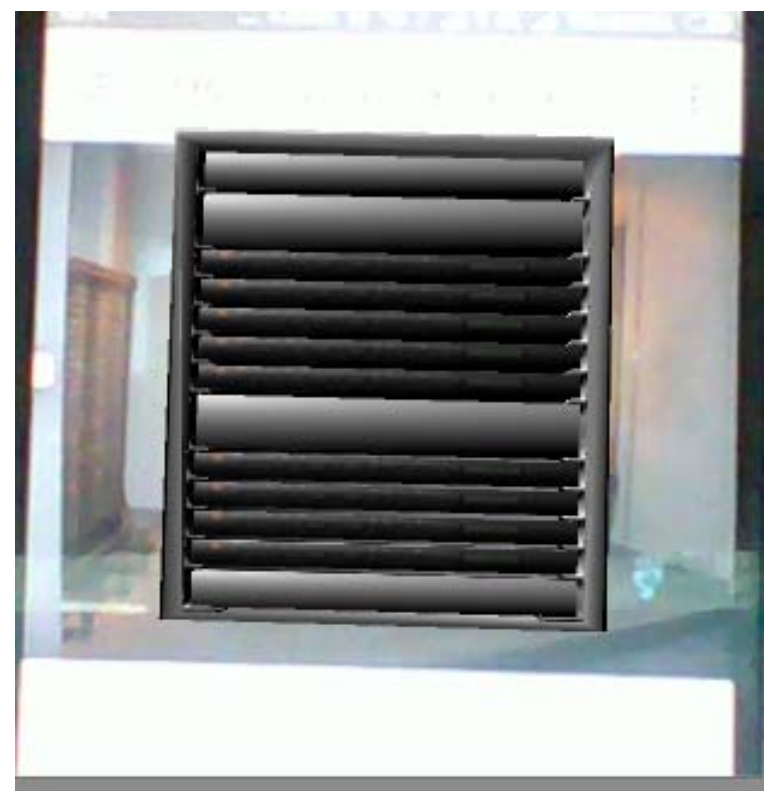

Gambar 13. Implementasi Augmented Reality Komputer ENIAC

Gambar 13 merupakan hasil penerapan Augmented Reality pada Flipbook berdasarkan marker komputer generasi pertama. Ketika telepon seluler melakukan pengindaian tepat di atas marker, objek 3 dimensi akan muncul seolah-olah ada di antara kita.

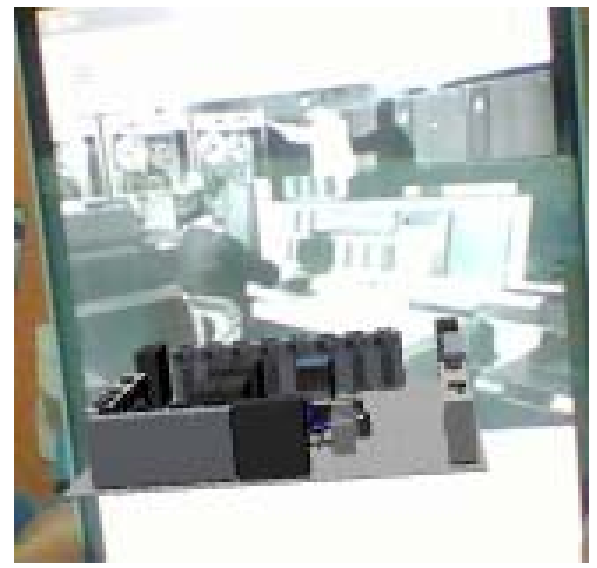

Gambar 14. Implementasi Augmented Reality Komputer Generasi ke 2
Gambar 14 merupakan hasil penerapan Augmented Reality pada Flipbook berdasarkan marker komputer generasi kedua yaitu mainframe IBM 370.

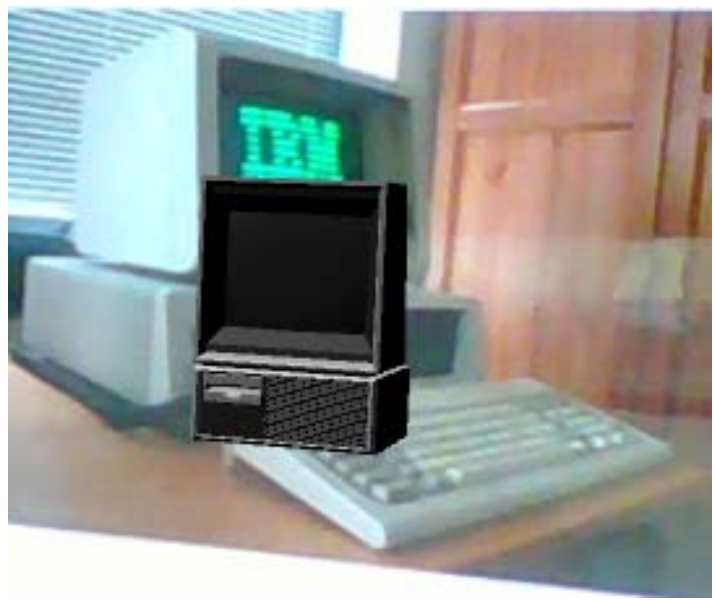

Gambar 15. Implementasi Augmented Reality Komputer Generasi ke 3

Gambar 15 merupakan hasil penerapan Augmented Reality pada Flipbook berdasarkan marker komputer generasi ketiga yaitu personal computer.

\section{Pengujian Aplikasi}

Pengujian aplikasi diperlukan sebagai bentuk dari validasi mengenai efektivitas dari penelitian. Peneliti melakukan validasi test case dengan cara membagikan kuesioner kepada peserta didik yang berjumlah 43 dalam satu kelas. Adapun hasil kuesioner tersebut adalah sebagai berikut:

Tabel 1. Usability Test Case

\begin{tabular}{llc}
\hline No Usability Test Case & Rata \\
\hline 1 Melakukan testing & \\
$\quad$ fungsionalitas button aplikasi & 8 \\
2 Pengecekan Objek 3d & 9 \\
3 Konsistensi perpindahan antar halaman & 8 \\
4 Tata letak komponen aplikasi & 9 \\
5 Visibilitas Objek 3d & 9 \\
6 Inovasi dalam pembelajaran & 8 \\
7 Melakukan tes responif aplikasi & 9 \\
8 Kegunaan dari aplikasi & 9 \\
9 & Entertainment & 10 \\
10 & Product Transfer Knowledge & 10 \\
& \\
\hline & Rata rata & $\mathbf{8 9}$
\end{tabular}


Tabel 1 menyatakan bahwa hasil penjumlahan rata-rata respons dari para peserta didik adalah sejumlah 89, di mana angka ini menunjukan bahwa penerapan Augmented Reality dengan media Flipbook dapat diterima dengan baik oleh mahasiswa dari sisi transfer knowledge dan sisi interaksi pembelajaran.

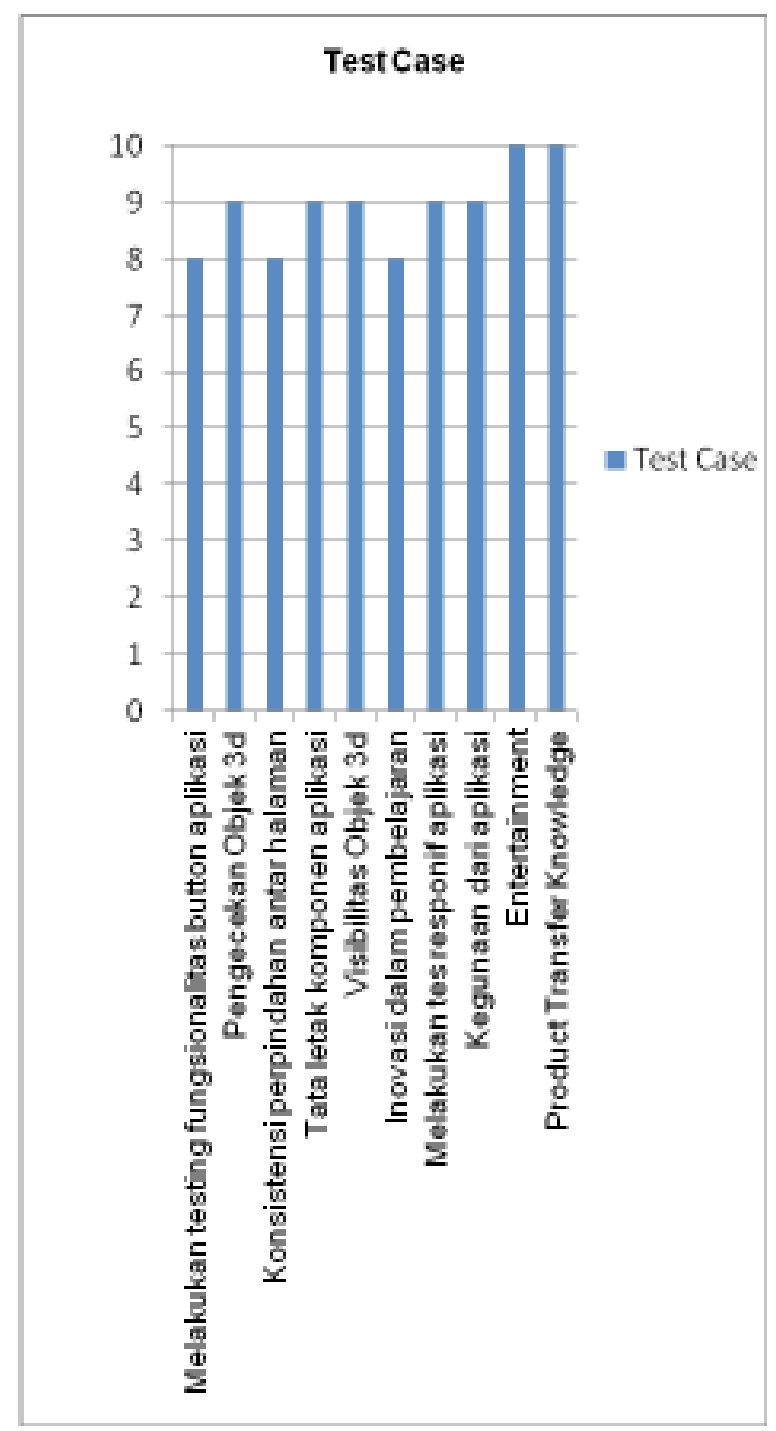

Gambar 16. Graphic Chart Hasil Usability Test Case

Berdasarkan Gambar 16, dapat disimpulkan bahwa hasil test case yang telah dilakukan menunjukkan bahwa transfer product knowledge dan entertainment yang mendapatkan nilai 10 dapat diartikan bahwa peserta didik puas dengan transfer knowledge dari pengembangan bahan belajar dan interaksi dalam proses belajar-mengajar.

\section{SIMPULAN DAN SARAN}

Teknologi Augmented Reality dapat diterapkan pada media Flipbook dengan pembelajaran jarak jauh, atau disebut juga dengan daring, sebagai upaya untuk meningkatkan inovasi pada proses belajar mengajar dalam menunjang tercapainya transfer knowledge yang baik. Sebagian besar responden yang terdiri dari peserta didik menyatakan bahwa inovasi yang dilakukan memberikan dampak yang positif dalam hal pemahaman lebih detail secara visual mengenai materi belajar dan proses pembelajaran menjadi lebih interaktif. Teknologi Augmented Reality memiliki potensi yang baik khususnya di bidang pendidikan untuk menunjang kegiatan belajar mengajar agar semakin baik.

Namun demikian, inovasi ini masih memiliki kekurangan. Beberapa responden masih merasakan kekurangan dari sisi antarmuka aplikasi, sebagian dari mereka merasa bahwa aplikasi yang dikembangkan masih sangat sederhana, tidak memiliki fitur tambahan yang sebenarnya bisa dilakukan untuk menambah nilai dari penelitian. Selain itu, objek 3 dimensi yang digunakan untuk teknologi Augmented Reality agar bisa diperbanyak lagi.

\section{PUSTAKA ACUAN}

\section{Buku}

Gagne, R.M. 1985. The Condition of Learning Theory of Instruction. New York: Rinehart.

Rosa, A. S. dan Shalahuddin, M. 2013. Rekayasa Perangkat Lunak. Bandung: Informatika.

\section{Jurnal/prosiding/disertasi/tesis/skripsi}

Aguston, R. L., dkk. 2016. Pemanfaatan Augmented Reality Pada Permainan Othello. Jurnal TEKNIKA, Vol. 5 Edisi 1, pp.1-9.

Arifitama, Budi; Syahputa, Ade. 2017. Cultural Heritage Digitalization on Traditional Sundanese Music Instrument Using Augmented Reality Markerless Marker Method. Jurnal Teknologi dan Sistem Komputer, Vol. 5 Edisi 3, p. 101-105. 
Azuma, R.T. 2017. Making Augmented Reality a Reality. Imaging and Applied Optics 2017 (3D, AIO, COSI, IS, MATH, pcAOP), OSA Technical Digest (online) (Optical Society of America, 2017), paper JTu1F.1.

Haryanti, F., Saputro, B. A. 2016. Pengembangan Modul Matematika Berbasis Discovery Learning Berbantukan Flipbook Untuk Meningkatkan Kemampuan Pemahaman Konsep Pada Materi Segitiga. Jurnal Pendidikan Matematika, pp. 147-161.

Hidayatullah, M. S., Rakhmawati, L. 2016. Pengembangan Media Pembelajaran Berbasis Flipbook Maker Pada Mata Pelajaran Elektronika Dasar di SMK Negeri 1 Sampang. Jurnal Pendidikan Teknik Elektro, pp. 83-88.

Mulyaningsih, N. N., Saraswati, D. L. 2017. Penerapan Media Pembelajaran Digital Book Dengan Kvisoft Flipbook Maker. Jurnal Pendidikan Fisika Universitas Muhammadiyah Metro, pp. 25-32.

Perez, S. R. 2017. Discovering Language Through Augmented Reality and The Interactive Digital White Board. Educare Electronic Journal, pp. 1-13.
Rasiman. 2014. Efektivitas Resource-Based Learning Berbantukan Flip Book Maker Dalam Pembelajaran Matematika SMA. Jurnal JKPM, Vol. 1 Edisi 2, pp 34-41.

Rikawarastuti., Anggreni, E. 2017. The Use of "Kak Ayu Dental Flipbool" in Oral Health Knowldege Improvement for Elementary School Students in Depok". Kesmas: National Public Health Journal, pp.163-167.

Lain-lain

Jacobs, Paul E. products/augmented-reality. www.qualcom.co.id. [online] 2012. http:// www.qualcomm.co.id/products/ augmented reality.

Vuforia, Getting Started Vuforia, https:// library.vuforia.com/ (Diakses tanggal 17 September 2017)

Wahyono, B. , Jalur dan Jenjang Pendidikan (Menurut UU Sisdiknas), http://www. pendidikanekonomi.com/2012/12/jalur-danienjang-pendidikan-menurut-uu.html (Diakses tanggal 12 Desember 2012). 